\title{
Almacenamiento de carbono en un bosque de Pinus pseudostrobus en Nuevo San Juan, Michoacán
}

\author{
José Antonio Ordóñez ${ }^{1}$ \\ Bernardus H.J. de Jong ${ }^{2}$ \\ Omar Masera $^{1}$
}

\begin{abstract}
RESUMEN
En el presente trabajo se utilizó el modelo dinámico $\mathrm{CO}_{2} F i x$ para Windows Ver. 1.2., para obtener la captura potencial de carbono en la comunidad de Nuevo San Juan (NSJ). El carbono total estimado en el largo plazo (250 años) fue de $217 \mathrm{tC} / \mathrm{ha}$; la biomasa (aérea y subterránea) con $74 \mathrm{tC} / \mathrm{ha}$, los productos con $49 \mathrm{tC} / \mathrm{ha}$ y el suelo con $94 \mathrm{tC} / \mathrm{ha}$. Se estimó que en el mismo plazo se tiene un potencial de captura de carbono en el bosque de la comunidad de $1.9 \mathrm{MtC}$ en sus 8,870 ha. Así mismo se realizaron análisis de sensibilidad de tres parámetros, para identificar la diferencia potencial en la captura de carbono (tiempo de vida de los productos, tasas de humificación y descomposición $\pm 30 \%$ del valor original). Por último, se describe la importancia del uso del modelo $\mathrm{CO}_{2} \mathrm{Fix}$ como una herramienta en el manejo forestal, especialmente para las plantaciones forestales. La simulación se basó, en lo posible, en datos disponibles localmente: (a) superficie del área de estudio; (b) manejo forestal: ciclos de aclareos, corta de regeneración y corta de liberación; existencias reales (E.R.), y volumen de madera extraído; (c) crecimiento del árbol: incremento corriente anual (ICA), diámetro, altura, edad e incremento medio anual (IMA); y (d) productos derivados como: papel, cajas de empaque, madera para construcción, madera para muebles, madera para energía y madera muerta.
\end{abstract}

PALABRAS CLAVE:

Captura de carbono, Nuevo San Juan, manejo forestal, modelo $\mathrm{CO}_{2} \mathrm{Fix}$, plantaciones forestales.

\begin{abstract}
In this work, the $\mathrm{CO}_{2} \mathrm{Fix}$ dynamic model for Windows Ver. 1.2 was utilized to obtain the potential carbon sequestering in the community Nuevo San Juan. Total carbon estimated in the long run (250 years) was $217 \mathrm{tC} / \mathrm{ha}$; the biomass (aerial and subterranean) with $74 \mathrm{tC} / \mathrm{ha}$, products with $49 \mathrm{tC} / \mathrm{ha}$ and soil with $94 \mathrm{tC} / \mathrm{ha}$. It was estimated that in the same time span, there is a potential for carbon sequestering in the community forest of $1.9 \mathrm{MtC}$ in tis $8,870 \mathrm{ha}$. At the same time, sensitivity analyses were carried out with three parameters to identify the potential difference in carbon sequestering (life time of the wood products, humification and decaying rates $\pm 30 \%$ of the original value). Finally, the importance of using the $\mathrm{CO}_{2} \mathrm{Fix}$ model as a tool for forest management is highlighted especially for forest plantations. The simulation was based, as feasible, in data available locally: (a) area surface in study; (b) forest management: thinning cycles, regeneration and liberation cuttings ; actual standing volume and volume extracted; (c) tree growth: current annual increment, diameter, height, age and annual average increment and, (d) manufactured products as: paper, packaging, construction lumber, wood for furniture, fire wood and dead wood.
\end{abstract}

KEY WORDS:

Carbon sequestering, Nuevo san Juan, forest management, $\mathrm{CO}_{2} \mathrm{Fix}$ Model, forest plantations. 


\section{INTRODUCCIÓN}

El cambio climático global, es uno de los problemas ecológicos más severos, que se propician por el incremento de las emisiones de gases de efecto invernadero (GEI). Este fenómeno tendría repercusiones particularmente graves para los ecosistemas naturales, coadyuvando a la pérdida y degradación de la riqueza biótica del planeta, la erosión de suelos, cambios en los patrones de evapotranspiración, contaminación de mantos acuíferos y otros fenómenos (Bolin, 1986; Wilson, 1999; Cherrill y McClean, 1995; Krysanova et al., 1998; Mander et al., 1998).

Se ha determinado que el dióxido de carbono $\left(\mathrm{CO}_{2}\right)$ es el principal $\mathrm{GEI}$, siendo los factores más importantes la producción de combustibles fósiles y el cambio en el uso del suelo (Schneider, 1989; Houghton, 1989; Goudie, 1990; Lashof y Ahuja, 1990; Mintzer, 1992; Dixon et al., 1994). En nuestro país los principales emisores de gases de efecto invernadero son el sector energía por el uso de combustibles fósiles con 83.8 Mega toneladas cúbicas ${ }^{(1)}$ (MtC) (Gay y Martínez, 1995), en segundo lugar el cambio en el uso del suelo y forestería con 30.2 MtC (Masera et al., 1995b; Masera et al., 1997, estiman 52.3 MtC, sin restar las tC absorbidas por arbustos y matorrales, por lo que se considera en este estudio la primera estimación) y en tercer lugar los procesos de la industria del cemento con 3.1 MtC (Gay y Martínez, 1995) dando un total de 117.1 MtC. El IPCC (1995), estima que las emisiones de México contribuyen con el $1.45 \%$ de de las emisiones totales de carbono que se dan en nuestro planeta cada año.

La desforestación y la degradación del recurso forestal han sido muy importantes en las últimas décadas. La tasa de desforestación, no se conoce con precisión y las estimaciones oscilan entre 370 y 670 mil ha año-1 para principios de los 90 's en bosques templados y selvas ${ }^{(2)}$. Masera et al. (1997) afirman que probablemente la tasa alta sea la correcta. De acuerdo con esta última estimación se tiene que para los bosques templados la tasa de desforestación es de $1 \%$ y para las selvas un $2 \%$ al año (Masera et al., 1995a).

Las causas que más impacto tienen en la desforestación son el cambio en el uso del suelo, conversión a praderas y a cultivos agrícolas, así como los incendios forestales y la tala irracional. Es por eso que los procesos de cambio de uso del suelo, ocupan el segundo lugar entre las fuentes de emisión de GEI a nivel nacional.

Los bosques tienen la posibilidad de mitigar los GEI por medio de la captura de carbono que se realiza en diferentes ecosistemas vegetales conocidos como sumideros, a pesar de ser, actualmente, fuentes netas de emisión de GEI (Masera, 1996; Ordóñez, 1998 y 1999). En efecto, la vegetación asimila dióxido de carbono atmosférico, por medio del proceso fotosintético. Los árboles en particular, asimilan y almacenan grandes cantidades de carbono durante toda su vida. Los bosques del mundo capturan y conservan más carbono que cualquier otro ecosistema terrestre y participan con el $90 \%$ del flujo anual de carbono entre la

1 Una mega tonelada (MtC) es igual a un millón de toneladas cúbicas

2 Actualmente existen inconsistencias en las definiciones de los tipos básicos de vegetación y superficie entre los diferentes inventarios forestales y entre diferentes instituciones (Masera, 1995b). Por ejemplo, el Primer Inventario Forestal, realizado entre 1961 y 1985, utilizó fotografías aéreas y muestreo intensivo de campo para el $52 \%$ de la superficie forestal -esencialmente las zonas arboladas con mayor valor comercial- e imágenes de satélite de baja resolución y fue procesado a escala 1:3,000,000 para el 48\% restante. El Inventario Forestal de Gran Visión se realizó con imágenes de satélite de baja resolución y fue procesado a escala 1:1,000,000 sin muestreos de campo. Finalmente, el Inventario Forestal Periódico utilizó imágenes de satélite de alta resolución pero con interpretación en papel, fue procesado a escala 1:250,000 e incluyó muestreos de campo de baja intensidad (Varela et al., 1995) 
atmósfera y la superficie de la tierra (Apps et al., 1993; Brown et al., 1993; Dixon et al., 1994).

Estimar con precisión la dinámica de los flujos netos de carbono entre los bosques y la atmósfera (es decir, el balance emisión-captura) es uno de los problemas abiertos más importantes en la discusión sobre cambio climático (IPCC, 1995; Lashof y Ahuja, 1990; Mintzer, 1992; Dixon et al., 1994). Esto es resultado del complejo ciclo biogeoquímico del carbono en los ecosistemas forestales (García y Ordóñez, 1999). En efecto, los procesos de captura-emisión son parte de un sistema con cuatro tipos generales de reservorios de carbono (vegetación -aérea y radicular- materia en descomposición, suelos, productos forestales), con tiempos de residencia y flujos asociados muy diferentes. Estos reservorios se encuentran estrechamente interrelacionados lo que hace necesario un enfoque sistémico conocido como: método del sistema total del carbono, (Apps et al., 1993; Dixon et al., 1994) y el uso de modelos de simulación. La problemática es particularmente crítica para los bosques tropicales, en donde no se tiene información buena de los contenidos de carbono en vegetación y suelo, ni se han podido parametrizar los modelos predictivos existentes (p.e. modelos como: GORCAM, CASFOR, LUCS; Mohren y Goldewijk, 1990; Nabuurs y Mohren, 1993; De Jong et al., 1995; Masera et al., 1997; Ordóñez, 1997, 1998 y 1999).

\section{Captura de carbono en los ecosistemas forestales}

La dinámica del carbono en los ecosistemas forestales es muy compleja, por lo que, para hacer una estimación de los cambios en el almacenamiento de carbono, es necesario analizar la cantidad de carbono en los distintos componentes que integran los ecosistemas y las transferencias de carbono entre ellos en el tiempo y el espacio. Esto implica analizar conjuntamente la dinámica del carbono en: vegetación (aérea y subterránea), suelo (incluyendo materia en descomposición) y productos forestales. Para obtener la dinámica temporal de la captura de carbono es necesario utilizar modelos de simulación.

En este estudio se integró toda la información que fue posible obtener localmente, complementándola con datos publicados de estudios de caso en ecosistemas similares para poder así ejecutar el modelo de simulación $\mathrm{CO}_{2} \mathrm{Fix}$ a fin de poder realizar una estimación de la dinámica de carbono en los bosques de la comunidad de Nuevo San Juan (NSJ).

El uso de modelos de simulación permite realizar las estimaciones de la dinámica de carbono de una manera ágil, y facilita la generación de escenarios alternativos a corto, mediano y largo plazo, así mismo un análisis de sensibilidad de ciertos parámetros (Mohren y Goldewijk, 1990; Nabuurs y Mohren, 1993; De Jong et al., 1995; Masera et al., 1997; Ordóñez, 1997, 1998 y 1999). Sin embargo, los modelos requieren de una multitud de parámetros que no siempre se pueden obtener a nivel local.

\section{Descripción general del área de estudio}

El municipio de Nuevo San Juan se localiza al sur de la región Purépecha en el centro occidente del Estado de Michoacán (Fig. 1) entre los paralelos 1921'00" y 1924'45" $\mathrm{N}$ y los meridianos $102^{\circ} 08^{\prime} 15^{\prime \prime}$ y $102^{\circ} 17^{\prime} 30^{\prime \prime} \mathrm{W}$. Tiene una extensión de 23,431.00 ha.

La Comunidad Indígena de Nuevo San Juan se ubica en el municipio de Nuevo San Juan Parangaricutiro, a 15 km al poniente de la ciudad de Uruapan. Administrativamente, forma parte del Centro de Apoyo Agropecuario y Forestal № 001 de Nuevo San Juan, del Distrito de Desarrollo Rural Integral №. 087, con 


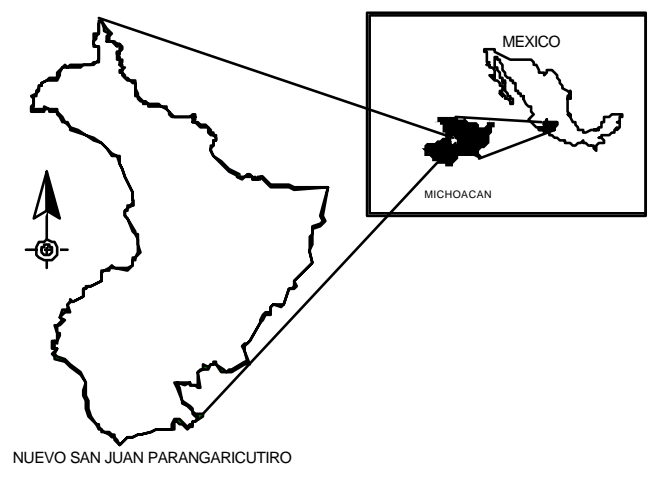

Figura 1. Localización del área de estudio

sede en Uruapan de la jefatura del Programa Forestal y de la Delegación Estatal de la Secretaría de Agricultura y Recursos Hidráulicos (SARH), en Morelia, Michoacán. Cuenta con una superficie de 18,318 ha, que representa el $78 \%$ del total municipal.

La región pertenece al Período Cuaternario y tiene rocas del medio superior volcánico de la Era Cenozoica. En el área se encuentran rocas ígneas de tipo andesititas, riolitas, basaltos, tobas, cenizas volcánicas, porfidios y brechas andesititas predominantemente. También rocas sedimentarias compuestas por material dendrítico, en proporción menor. En la región abundan los conos cineríticos grandes y pequeños, barrancas, llanuras volcánicas y algunos valles, con altitudes que van de los 1,500 a 3,250 msnm.

Los suelos que dominan el área corresponden, según el sistema FAOUNESCO, a andosol vítrico, regosol eutrico, litosol, luvisol crómico y cambisol eútrico (Cuanalo et al., 1989). La hidrología de la región está determinada por un patrón de drenaje heterogéneo, de forma radial en los volcanes, dendrítico en las lavas y lateral en los llanos.
De acuerdo con el sistema de clasificación de Köppen modificado por García (1981) y en las cartas de clima elaboradas por la Secretaría de Programación y Presupuesto (SPP), Instituto Nacional de Estadística Geografía e Informática (INEGI) y la Dirección General de Geografía (DGG), el clima es templado húmedo $(\mathrm{C}(\mathrm{m})(\mathrm{w})$ big con variantes) con abundantes lluvias en verano y lluvia invernal menor del 5\%; Existe una precipitación anual entre 1,500 y $2,000 \mathrm{~mm}$, una frecuencia de heladas entre 20 y 40 días al año y una frecuencia de granizadas de 3 días al año.

La temperatura media anual es de 12 a $14^{\circ} \mathrm{C}$ en los cerros más altos de la región (Tancítaro y Paricutín, entre otros); de 14 a $16^{\circ} \mathrm{C}$ en la mayor parte de la región y de 16 a $18^{\circ} \mathrm{C}$ en el área más cercana al pueblo de San Juan Nuevo (García, 1981).

Vegetación. La vegetación en su mayor parte está representada por bosque de pino y bosque de pino-encino. Madrigal (1982) menciona la existencia de bosque de oyamel y menciona la presencia de las coníferas Abies religiosa var. emarginata, Pinus douglasiana, P. lawsonii, P. leiophylla, $P$. maximinoi y $P$. michoacana. Las especies de encino registradas por Bello y Labat (1987) para el municipio son Quercus candicans, Q. castanea, Q. crassipes, $Q$. laurina, $Q$. obtusata y $Q$. rugosa.

Uso del suelo. Los bosques cubren una superficie total de 10,653 ha $(59 \%$ de la superficie total). Los recursos forestales son considerados como el recurso más importante para la comunidad de Nuevo San Juan, toda vez que de él se aprovecharon en 1995, entre 90,000 y $100,000 \mathrm{~m}^{3}$ por año, sosteniendo una planta productiva de más de 850 empleos en los aspectos de extracción, abastecimiento, industrialización y comercialización de los principales productos maderables. El uso del suelo en la comunidad indígena de Nuevo San Juan se presenta en la tabla 1. 
Tabla 1. Uso del suelo en la comunidad indígena de Nuevo San Juan, Michoacán (SARH, 1988)

\begin{tabular}{lc}
\hline \multicolumn{1}{c}{ USO DEL SUELO } & $\begin{array}{c}\text { SUPERFICIE } \\
(\mathrm{Ha})\end{array}$ \\
\hline Forestal: & \\
Bosques densos & 2,323 \\
Bosques abiertos & 6,554 \\
Encinares y vegetación en malpaís & 1,776 \\
$\quad$ Total forestal & 10,653 \\
\hline Agropecuario: & \\
Granos y forrajes & 4,020 \\
Frutales & 1,214 \\
Descanso & 800 \\
$\quad$ Total agropecuario & 6,034 \\
\hline Lavas y cenizas volcánicas & 1,161 \\
\hline Sin definir & 288 \\
\hline Total & 18,318 \\
\hline
\end{tabular}

Como segunda actividad importante se encuentra la actividad agropecuaria, la cual ocupó para 1995 una superficie de 6,034 ha. De ellas la mayor parte se aprovecha con fines agrícolas con cultivos de maíz, avena y en menor superficie con plantaciones de frutales como aguacate y durazno. El resto de la superficie se encuentra bajo descanso o cubierto por lava y una pequeña parte actualmente no se aprovecha, debido a que presenta fuertes pendientes dificultando el manejo de los cultivos, la labranza y las labores de cultivo así como la extracción de la cosecha.

Manejo forestal. La comunidad de NSJ inició, desde 1988, un modelo de manejo forestal, con énfasis en la organización comunal, el establecimiento de una industria de transformación, reinversión de utilidades y capacitación permanente del personal técnico y administrativo. Desde el inicio del programa, la comunidad se ha propuesto como meta principal el manejo del arbolado, permitiendo su extracción y regeneración. Con base en un estudio del potencial dasonómico se establecieron los programas de manejo que abarcan los aspectos de protección, fomento e industria forestal. Además se ha hecho una división de áreas para los aprovechamientos. Así, de las aproximadamente 11,000 ha forestales, se aprovecha un promedio de 1,000 ha al año para la extracción de 80,000 a 100,000 $\mathrm{m}^{3}$ de las especies de pino (Pinus spp), oyamel (Abies religiosa), encino (Quercus spp) y otras especies (SARH, 1988).

A diferencia de otras comunidades de la región, en NSJ la relación entre el aprovechamiento real $y$ el volumen autorizado se ha incrementado del $80 \%$ para 1988-1989 al 100\% para 1993-1994. Tal incremento se debe al avance organizativo en el manejo del bosque, extracción y su industrialización, ayudado en mucho por la integración que se tiene de los servicios técnicos a través de la unidad de conservación y desarrollo forestal, la cual está integrada como una área más de trabajo dentro del organigrama de la comunidad. 
Un aspecto relevante en la actividad forestal de la comunidad han sido las plantaciones forestales para reforestación, especialmente en las áreas degradadas con arenales y terrenos abandonados. En un lapso de 5 años se han establecido viveros locales, con la colecta de semilla de los bosques comunales, desde donde se han reforestado cerca de 1,300 ha.

El bosque natural de la comunidad indígena de NSJ se aprovecha siguiendo el método conocido como Método de Árboles Padres (Grijpma, 1984), que consiste en la remoción de un porcentaje de arbolado, dejando en pie como árboles padres a los mejores individuos, distribuidos en toda el área o en pequeños grupos, con el objeto de asegurar el establecimiento de la regeneración natural.

En NSJ el bosque se encuentra dividido en rodales que son áreas del bosque formadas por árboles de una misma edad, aproximadamente, 0 de diferentes edades que tienen factores 0 características comunes como: pendiente, exposición al sol y tipo de suelo. Los rodales se pueden dividir en subrodales si se comparten características distintivas en el área.

El bosque se aprovecha con un turno de 50 años con un tratamiento cada 10 años: tres aclareos, una corta de regeneración y una corta de liberación.

\section{Descripción general del modelo}

El modelo de fijación de carbono $\mathrm{CO}_{2} \mathrm{Fix}$, fue desarrollado inicialmente por Mohren y Goldewijk en el Instituto de Investigaciones Forestales y de Ecología Urbana de Holanda en 1990. Está basado en una simulación del ciclo del carbono para rodales (stands) forestales bajo manejo silvícola. Con el modelo se puede calcular el carbono total capturado a nivel de una plantación.
El modelo original fue programado en Fortran 77 por lo que hubo que adaptarlo a interfaces gráficas usando Borland $\mathrm{C}^{+}$ Ver. 4.5. De esta forma el usuario sin mucha experiencia puede acceder $y$ trabajar de forma iterativa con el modelo. Esta tarea de adaptación y mejora del modelo original se llevó a cabo entre el Laboratorio de Bioenergía del Instituto de Ecología de la UNAM y el Instituto Forestal y de Investigación Natural de Holanda y resultó en la versión 1.2 del modelo $\mathrm{CO}_{2} \mathrm{Fix}$ para Windows (Mohren et al., 1997).

El modelo $\mathrm{CO}_{2} \mathrm{Fix}$ se ha aplicado en diferentes ecosistemas forestales en el mundo, incluyendo: bosque tropical lluvioso, bosque boreal y bosque templado deciduo con una representación de sistemas de silvicultura tradicional como el abeto Norway spruce en las montañas centrales de Europa y Douglas-fir en el pacífico noroeste de los Estados Unidos; el abeto slash en Brasil, Pinus caribbea en Brasil y Venezuela y Pinus radiata en Nueva Zelanda y Australia (Nabuurs y Mohren, 1993).

\section{OBJETIVO}

Estimar el potencial de captura de carbono en un bosque templado utilizando el modelo de simulación $\mathrm{CO}_{2}$ Fix (Mohren y Goldewijk, 1990; Nabuurs y Mohren, 1993; De Jong et al., 1995; Masera et al., 1997; Ordóñez, 1997, 1998 y 1999).

\section{Contribución de este estudio al conocimiento de la captura de carbono}

En el país, son muy pocos los estudios de caso realizados sobre la estimación del potencial de captura de carbono en ecosistemas forestales. Por este motivo, el presente estudio contribuye a: (a) desarrollar un método de estimación del potencial de captura carbono, basado en un modelo de 
simulación; (b) indicar los parámetros necesarios para realizar la estimación; (c) sugerir estudios específicos para determinar parámetros que no han sido cuantificados a nivel regional y (d) mostrar el potencial de captura de carbono que tiene un bosque templado del centro occidente del país. Una aportación adicional del estudio es sugerir un método reproducible para obtener la curva de incremento de especies forestales.

\section{Los análisis de sensibilidad realizados sobre cuatro grupos de parámetros claves, carbono contenido en humus, tiempo de residencia en productos forestales, coeficientes de humificación y descomposición y curvas de incremento (ICA), refuerzan la importancia de realizar más estudios detallados a nivel local. Específicamente, habrá que prestar atención especial a una determinación local o regional de los coeficientes de humificación y descomposición, puesto que presentan la mayor sensibilidad en los valores de la captura de carbono con respecto a la estimación base.}

\section{METODOLOGÍA}

Para realizar la estimación de captura de carbono del presente estudio se obtuvieron, en primera instancia, los datos generales del plan de manejo forestal, la superficie forestal, volumen de extracción, productos, incremento corriente anual (ICA), incremento medio anual (IMA), existencias reales (ER), edad promedio, altura, diámetro, ciclo de corta, ciclo de rotación, aclareos, corta de regeneración, corta de liberación. Una vez integrados los datos de diferentes rodales, se procedió a obtener una curva de crecimiento con todos los valores de los rodales, a los datos se les sometió a un análisis estadístico, con la aplicación de regresiones (lineal y exponencial) para utilizar la que mejor represente el comportamiento (crecimiento).
Una vez terminado el análisis estadístico y obtenida la curva de crecimiento, se procedió a integrar los valores al modelo $\mathrm{CO}_{2} \mathrm{Fix}$, y se realizaron los cálculos integrativos de la especie, para estimar la captura de carbono en biomasa, productos, suelo y carbono total.

Parámetros: Los parámetros fueron extraídos del estudio dasonómico del plan de manejo forestal de la comunidad indígena de NSJ (SARH, 1988). Uno de los parámetros más importantes para el modelo es la curva de crecimiento de la especie analizada, es decir el ICA por categoría de edad. Estos datos no son accesibles directamente de los planes de manejo forestal por lo general, por lo que se requiere un trabajo intenso de síntesis e integración de la información de base. En el presente estudio se obtuvo la curva del ICA a partir del análisis estadístico del crecimiento registrado en 210 rodales y subrodales que integran el bosque de la NSJ. Parámetros fisiológicos (p.e. el incremento en volumen de las ramas, las raíces y el follaje, respecto al tronco) y contenido de carbono en suelo, detritus y humus, no estaban disponibles en el plan de manejo, por lo que se utilizaron datos de estudios de caso comparativos a nivel nacional e internacional (De Jong et al., 1997; Nilsson y Schopfhauser, 1995; Nabuurs y Morhen, 1993).

Escenarios alternativos: Con los datos obtenidos, se generaron dos escenarios: escenario (a) se prolongó el turno de 50 a 80 años y escenario (b) se consideró que todo lo que se extrae del bosque se transforma en productos con un tiempo de vida media de 100 años, manteniendo el turno original de 50 años.

Análisis de sensibilidad: Dadas las incertidumbres y rango de variación de los parámetros necesarios para obtener la captura de carbono se consideró conveniente realizar un análisis de 
sensibilidad. Para este fin se seleccionaron tres tipos de parámetros sobre los que se estima existe la mayor incertidumbre en la estimación del potencial de captura de carbono en NSJ. Se aplicaron variaciones en sus valores de $-30 \%$ y $+30 \%$ para compararlos con los valores base. El porcentaje de variación se aplicó a los siguientes parámetros:

\section{a) Carbono contenido en el humus}

b) Tiempo de residencia promedio en los productos:

- tiempo de residencia promedio de madera muerta en el bosque

- tiempo de residencia promedio del papel

- tiempo de residencia promedio del aglomerado

- tiempo de residencia promedio de madera para energía,

- tiempo de residencia promedio para empaque

- tiempo de residencia promedio para la construcción

c) Coeficientes de humificación y descomposición:

- tasa de humificación

- tasa de residencia promedio del detritus

- tasa de residencia promedio del humus estable

Adicionalmente, se realizó un análisis de sensibilidad sobre los valores de la curva de ICA derivada estadísticamente, para el periodo entre 0 y 15 años. La razón de este procedimiento es que en NSJ no se tienen registrados rodales con estas edades, por lo que existe cierta incertidumbre sobre la correspondencia entre la regresión estadística y los valores reales en esta parte de la curva de incremento. Específicamente, se observa que, para otras especies de Pinus, los máximos del incremento ocurren muchas veces en el año 15 y no en el 5 como se estableció para este estudio.

\section{RESULTADOS}

Comparando las curvas de incremento del $P$. pseudostrobus, con cuatro especies ( $P$. caribea, $P$. elliottii, $P$. radiata y $P$. taeda) cuyo ICA se conoce (Morhen et al., 1997), se encontró que los incrementos correspondientes al año 5 representan entre el $25 \%$ y el $53 \%$ del valor al año 15, mientras que los incrementos al año 10 representan entre el $71 \%$ y el $92 \%$ del valor al año 15 .

A continuación se describen los principales resultados obtenidos de los cálculos realizados por el modelo $\mathrm{CO}_{2} \mathrm{Fix}$ para Windows Ver. 1.2., observando lo siguiente:

a) El balance de carbono en toda el área de estudio (considerada por el modelo como una plantación) se ilustra en la figura 2. Se aprecia el contenido e incremento de carbono en la biomasa, en el suelo, en los productos y la suma de estos tres almacenes que representa el carbono total del bosque.

En la misma figura se aprecia que a los 80 años la captura de carbono en biomasa y suelo comienza a estabilizarse, mientras que el carbono en productos alcanza esta estabilidad a los 100 años, debido a que el tiempo de producción y descomposición de los productos es diferente al ciclo natural del carbono en el ecosistema forestal. La captura total de carbono crece de forma constante entre los 50 y 100 años y comienza a estabilizarse a partir de este último año.

b) El balance de carbono en un rodal está representado en la figura 3; se aprecia el incremento y decremento cíclico, es decir, la dinámica del carbono en cada uno de los diferentes almacenes. La biomasa, el suelo y los productos presentan un incremento escalonado, donde cada escalón representa cada 


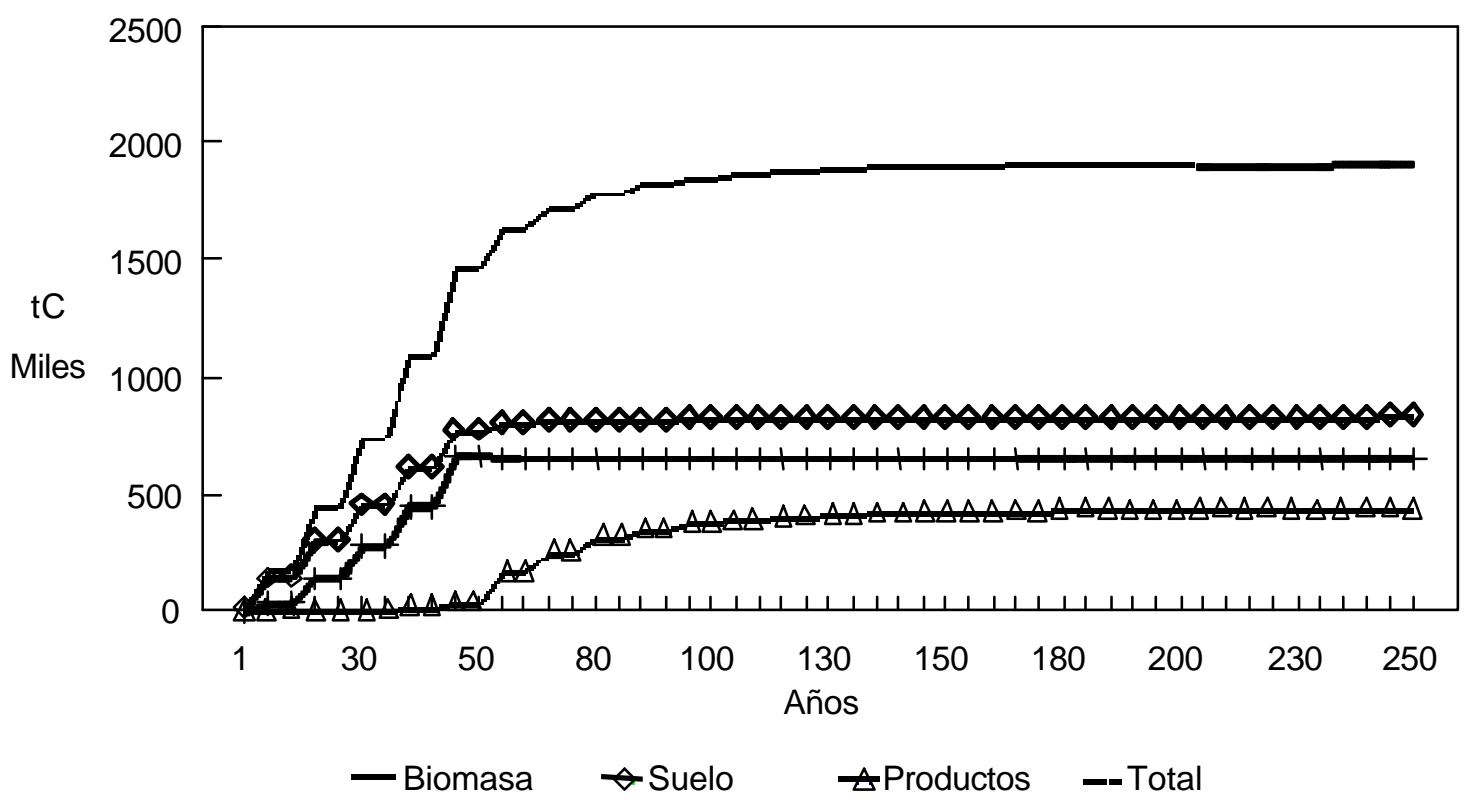

Figura 2. Balance del carbono contenido en la plantación de Pinus de NSJ

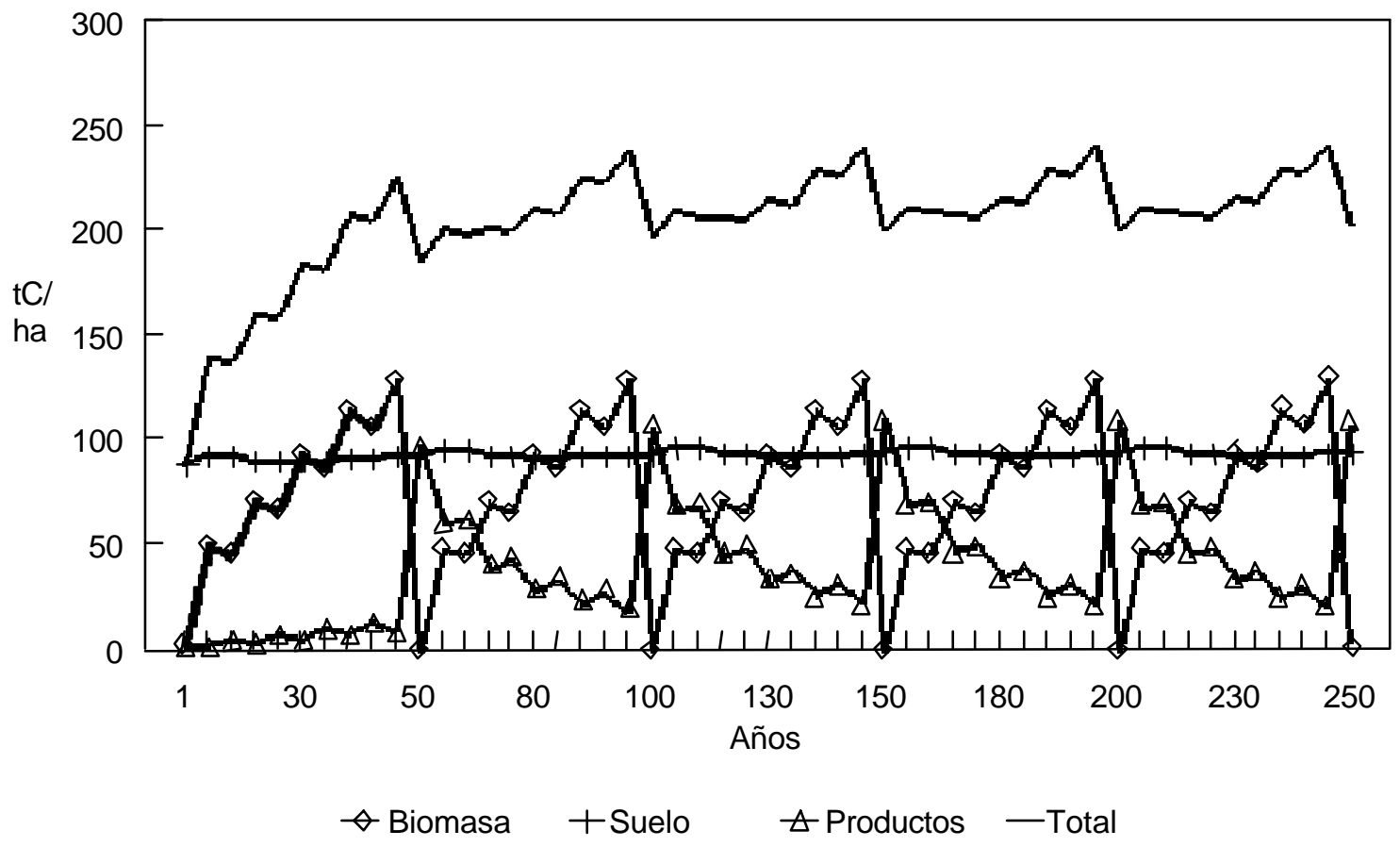

Figura 3. Balance de carbono en un rodal de Pinus en NSJ 
uno de los cinco tratamientos a los que se ve sometido el rodal. Al realizarse la corta de liberación (a los 50 años) y al ser removida la biomasa forestal, el contenido de carbono en la biomasa decrece hasta cero, mientras que el carbono en los productos y el suelo aumenta. Se observa que el carbono en el suelo, desde su inicio y hasta cinco turnos (250 años) después, se mantiene en cantidades constantes que solo fluctúan al término de cada turno (cada 50 años). Por otra parte se observa un incremento del carbono en productos después del primer turno. A partir de entonces, este reservorio presenta un comportamiento cíclico.

El potencial de captura total de carbono estimado para el bosque natural de la C.I. de NSJ mediante el empleo del modelo $\mathrm{CO}_{2}$ Fix fue de $1.5 \mathrm{MtC}$ a los 50 años, en una superficie de 8,870 ha de Pinus (Tabla 2, Fig. 4). En la tabla 2, se observa que a partir del primer turno, la biomasa presenta un incremento constante en los valores del contenido de carbono hasta los 100 años, momento en que se estabiliza. El contenido de carbono en suelo comienza a estabilizarse a partir del año 60 y se incrementa ligeramente respecto al tiempo; en cuanto al contenido de carbono en los productos, es hasta el año 2000 en que comienza a estabilizarse (Fig. 4).

Respecto al contenido de carbono por hectárea, se obtuvo que a largo plazo, la captura total unitaria alcanza $217 \mathrm{tC} / \mathrm{ha}$, de los cuales $94 \mathrm{tC} / \mathrm{ha}$ provienen del suelo, $74 \mathrm{tC} / \mathrm{ha}$ de biomasa y $49 \mathrm{tC} / \mathrm{ha}$ de productos (Tablas 3 y 4 ).

\section{Escenarios alternativos}

a) Al prolongar el turno a 80 años se observó que la captura total de carbono en el bosque a los cincuenta años era de $0.9 \mathrm{MtC}$ mientras que en el turno de 50 años era de $1.5 \mathrm{MtC}$; también se observó que al término del turno de 80 años la captura total de carbono fue de 1.6 MtC (Fig. 5), todavía menos que la captura del bosque con el turno original de 50 años. Sólo en el largo plazo la captura de carbono con un ciclo de 80 años resulta marginalmente mayor que en el ciclo original.

Tabla 2. Captura potencial de carbono en el bosque natural de NSJ

\begin{tabular}{rcccc}
\hline AÑOS & $\begin{array}{c}\text { BIOMASA } \\
\left(10^{3} \mathrm{tC}\right)\end{array}$ & $\begin{array}{c}\text { SUELO } \\
\left(10^{3} \mathrm{tC}\right)\end{array}$ & $\begin{array}{c}\text { PRODUCTOS } \\
\left(10^{3} \mathrm{tC}\right)\end{array}$ & $\begin{array}{c}\text { TOTAL } \\
\left(10^{3} \mathrm{tC}\right)\end{array}$ \\
\hline 0 & 0 & 0 & 0 & 0 \\
10 & 35.9 & 141.1 & 0 & 177.1 \\
20 & 139.1 & 301.1 & 2.2 & 442.4 \\
30 & 278.3 & 458.3 & 8.5 & 745.1 \\
40 & 455.5 & 616.1 & 19.1 & $1,090.8$ \\
50 & 663.7 & 776.2 & 33.9 & $1,474.1$ \\
60 & 661.9 & 810.4 & 168.7 & $1,641.1$ \\
70 & 661.1 & 815.7 & 255.1 & $1,732.1$ \\
80 & 660.6 & 819.2 & 311.8 & $1,791.7$ \\
90 & 660.2 & 821.6 & 349.5 & $1,831.3$ \\
100 & 659.8 & 823.3 & 374.8 & $1,858.1$ \\
150 & 659.8 & 828.1 & 421.7 & $1,909.7$ \\
200 & 659.8 & 831.2 & 430.3 & $1,921.4$ \\
210 & 659.8 & 831.7 & 431.0 & $1,922.6$ \\
250 & 659.8 & 833.7 & 432.2 & $1,925.8$ \\
\hline
\end{tabular}




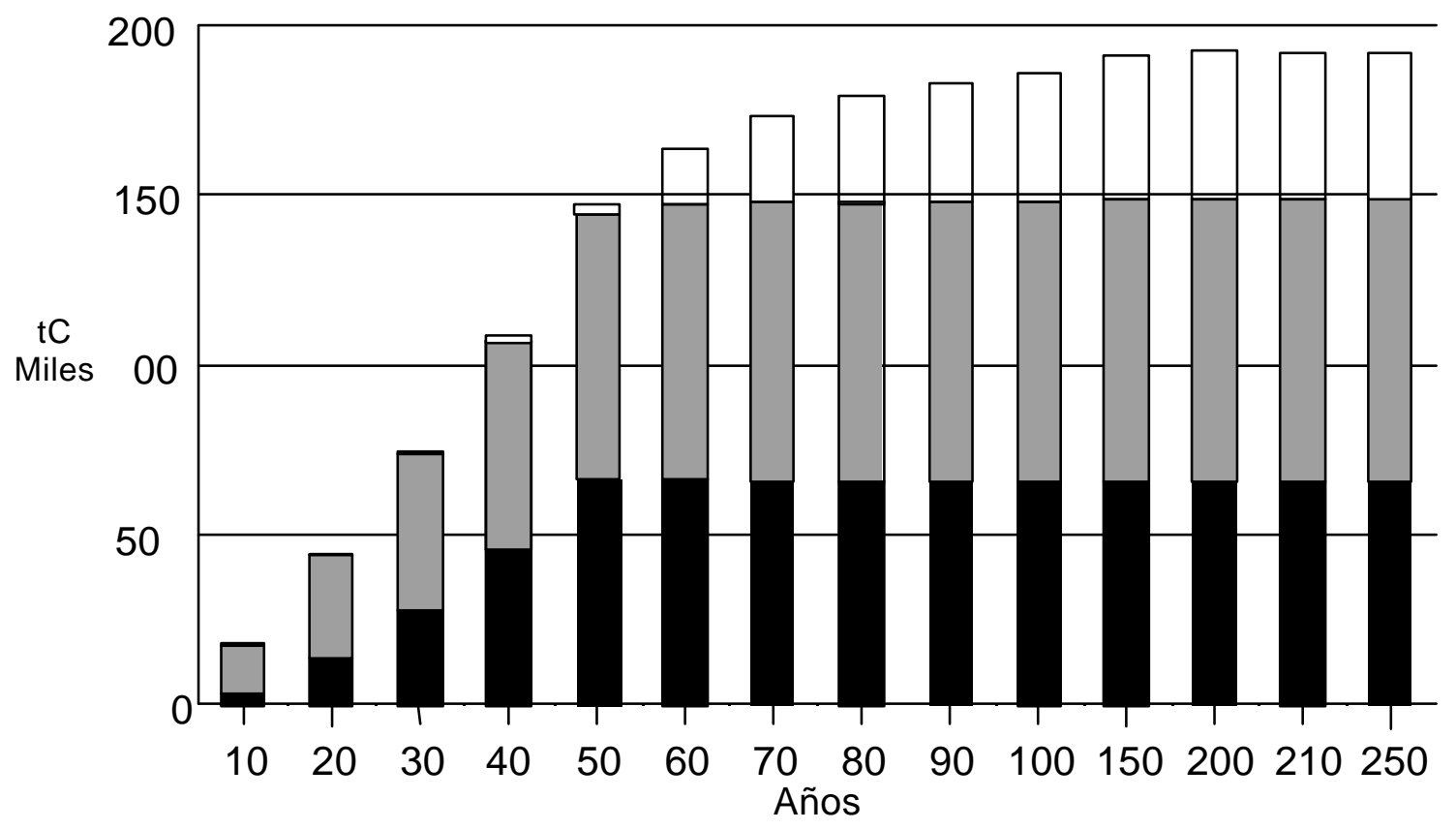

$\square$ Productos $\square$ Suelo $\square$ Biomasa

Figura 4. Captura potencial de carbono en el bosque natural de NSJ

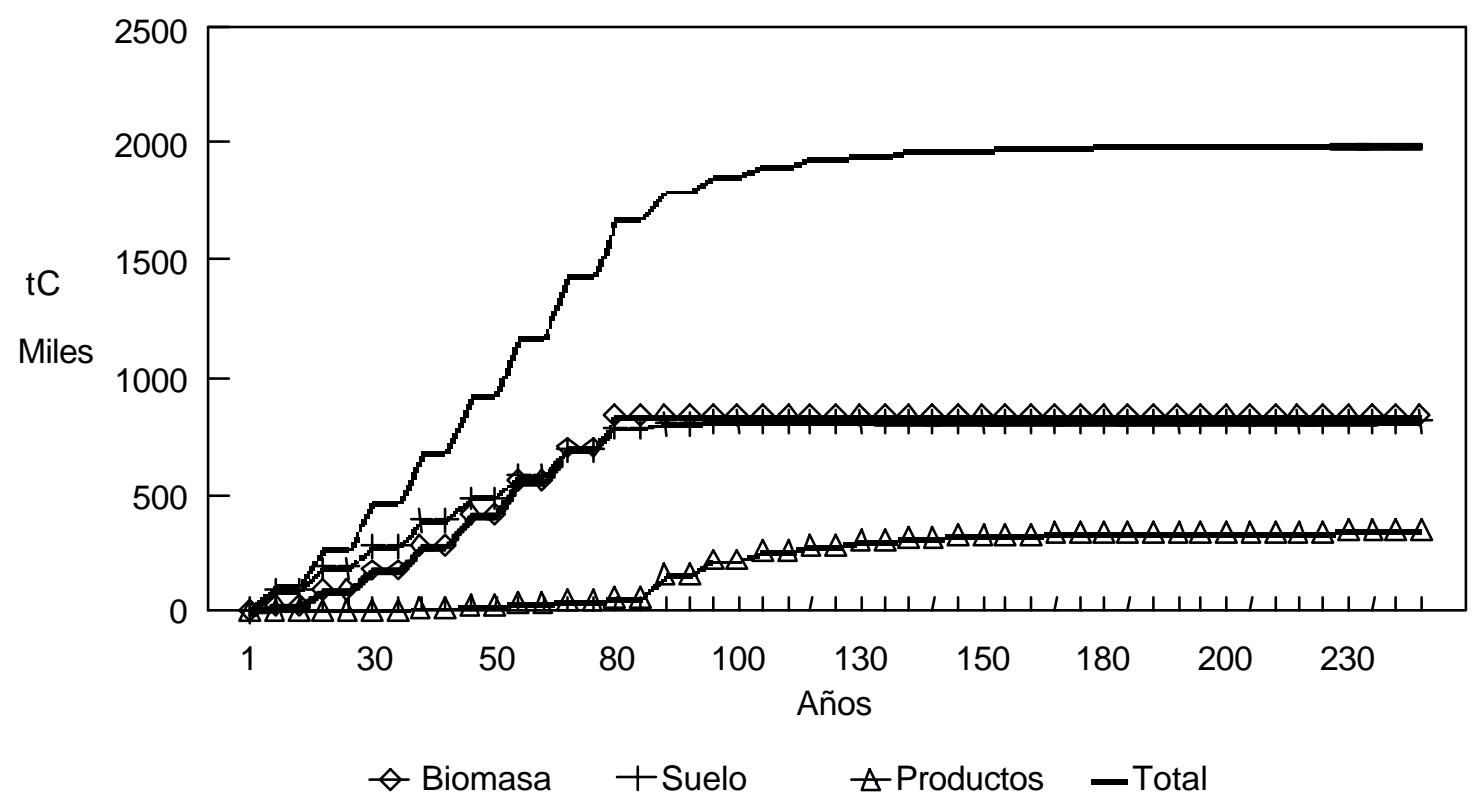

Figura 5. Captura de carbono en la plantación de NSJ, con un turno de 80 años 
Tabla 3. Balance de carbono en el bosque natural de NSJ por ha

\begin{tabular}{ccccc}
\hline AÑOS & $\begin{array}{c}\text { BIOMASA } \\
\text { (tC/ha })\end{array}$ & $\begin{array}{c}\text { SUELO } \\
(\mathrm{tC} / \mathrm{ha})\end{array}$ & $\begin{array}{c}\text { PRODUCTOS } \\
(\mathrm{tC} / \mathrm{ha})\end{array}$ & $\begin{array}{c}\text { TOTAL } \\
(\mathrm{tC} / \mathrm{ha})\end{array}$ \\
\hline 10 & 4 & 16 & 0 & 20 \\
30 & 16 & 34 & 0 & 50 \\
40 & 31 & 52 & 1 & 84 \\
50 & 51 & 69 & 2 & 123 \\
60 & 75 & 88 & 4 & 166 \\
70 & 75 & 91 & 19 & 185 \\
80 & 75 & 92 & 29 & 195 \\
80 & 74 & 92 & 35 & 202 \\
90 & 74 & 92 & 35 & 202 \\
100 & 74 & 93 & 39 & 206 \\
150 & 74 & 93 & 42 & 209 \\
200 & 74 & 93 & 48 & 215 \\
210 & 74 & 94 & 49 & 217 \\
250 & 74 & 94 & 49 & 217 \\
\hline
\end{tabular}

Tabla 4. Captura de carbono en el bosque natural de NSJ por ha en el largo plazo (250 años)

\begin{tabular}{lc}
\hline \multicolumn{2}{c}{ CAPTURA DE CARBONO tC/ha } \\
\hline Biomasa & 74 \\
Productos & 49 \\
Suelo & 94 \\
Total & 217 \\
\hline
\end{tabular}

b) Al considerar que todo el aprovechamiento del bosque se almacena en productos con un tiempo de vida de 100 años, la captura de carbono continúa creciendo indefinidamente en lugar de estabilizarse a lo largo del tiempo. Por ejemplo, el carbono total almacenado se incrementa de $1.4 \mathrm{MtC}$ a los 50 años a $3.0 \mathrm{MtC}$ a los 250 años (Fig. 6 y 7 ). 


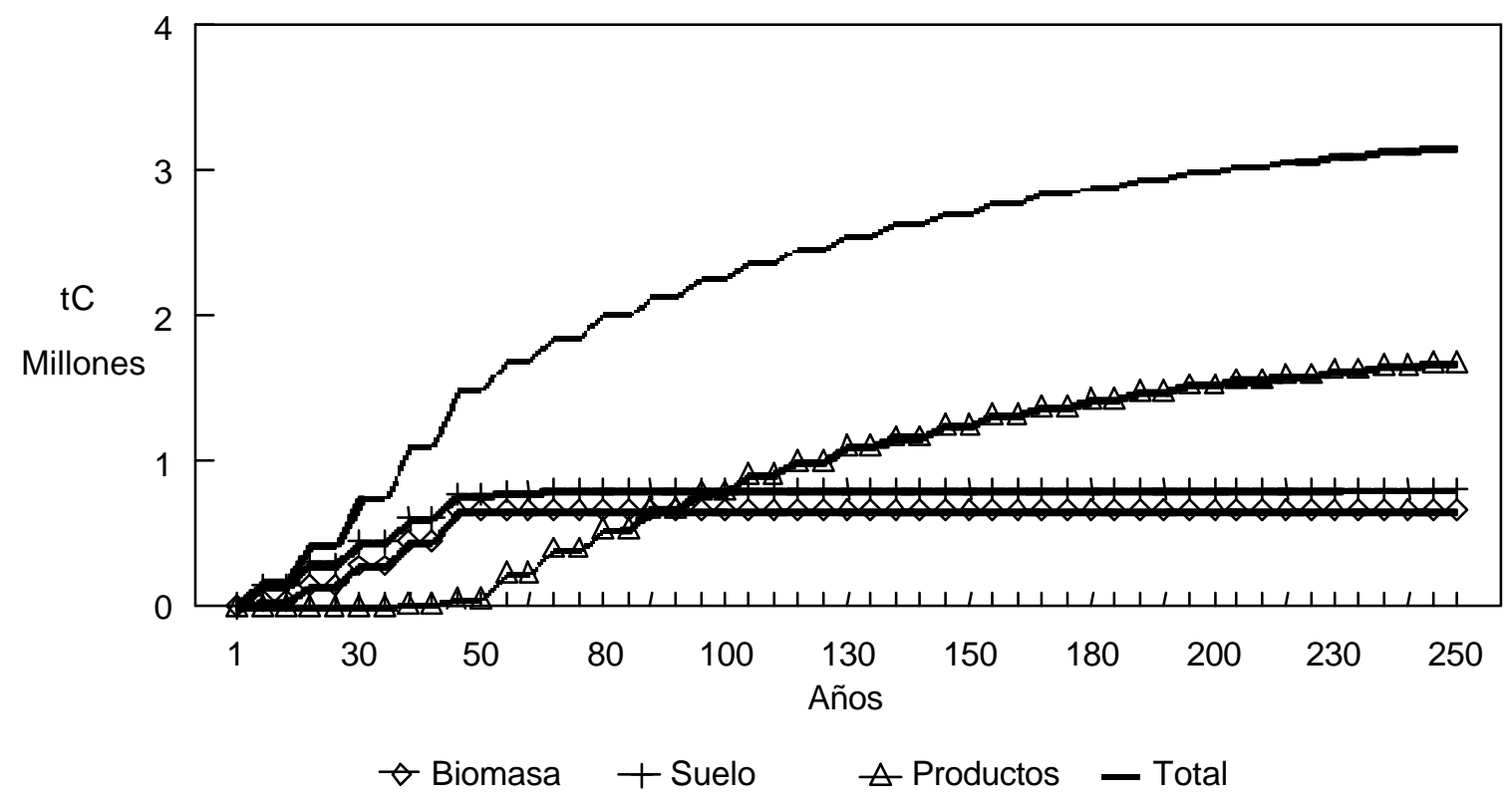

Figura 6. Contenido de carbono para un escenario donde los productos tienen un tiempo de duración de 100 años

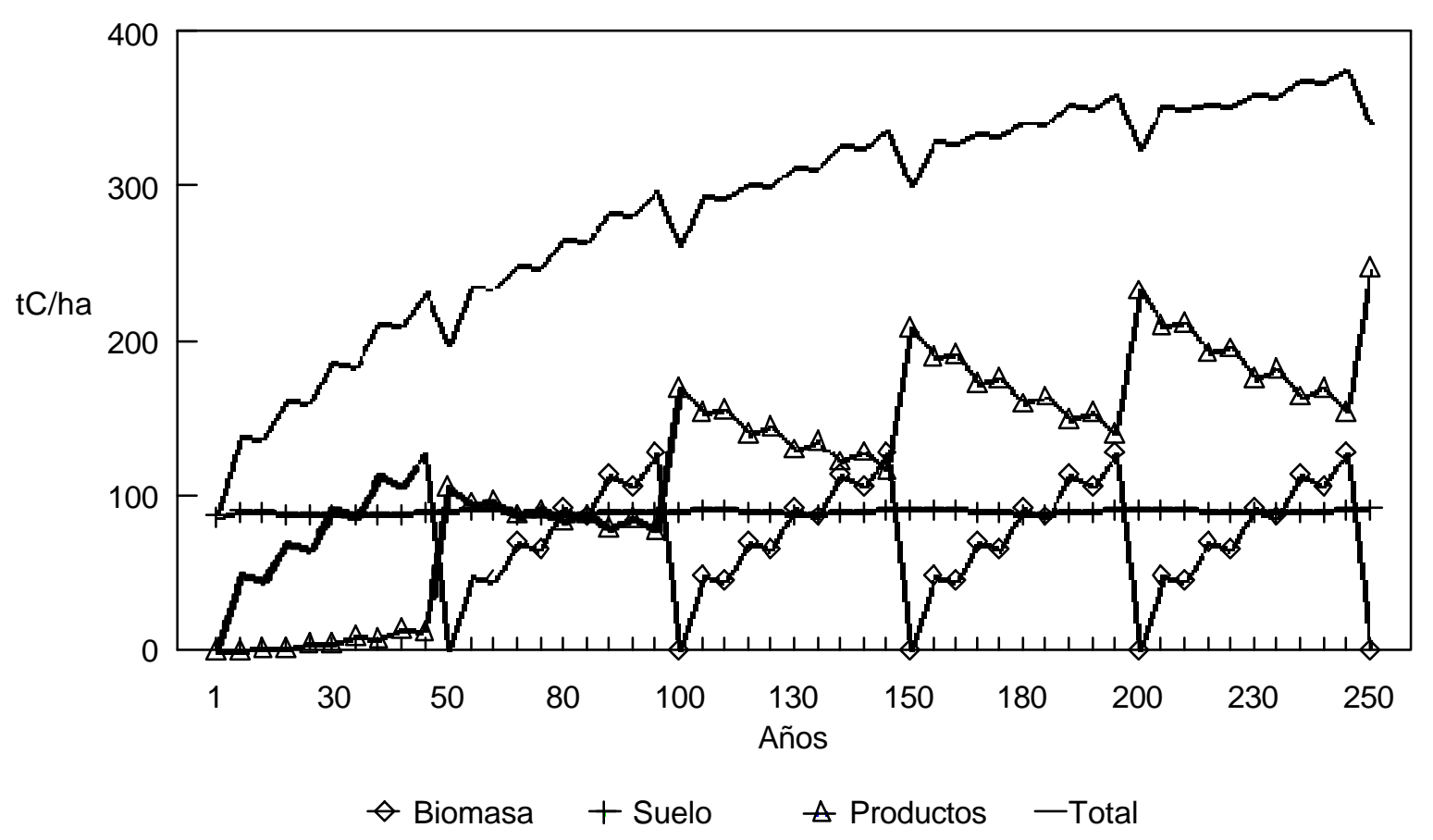

Figura 7. Contenido de carbono en un rodal con productos que tienen una duración de 100 años 
La sensibilidad observada en el análisis es como sigue:

a) Para el carbono contenido en la biomasa inicial del humus se obtuvo una diferencia de $\pm 100 \mathrm{KtC}$ con respecto a la estimación base. Esta diferencia tiende a estabilizarse en el largo plazo (cerca de los 500 años) (Fig. 8). Es decir que, aún cuando el desarrollo del bosque comience con una diferencia de más 30\% y de menos 30\% en el contenido de carbono en el humus en el largo plazo, el carbono total será aproximadamente el mismo.

b) Para el tiempo de residencia promedio en los productos se obtuvo una diferencia de $\pm 100 \mathrm{KtC}$ en el largo plazo, considerado de 250 años (Fig. 9). Estas diferencias representan el equivalente a $\pm 5 \%$ de la captura de carbono con respecto a la estimación base, por lo que podemos concluir que no es tan crítico utilizar estimaciones generales de los tiempos de residencia ante la ausencia de datos locales

c) Para los coeficientes de humificación y descomposición se obtuvo una diferencia de $\pm 300 \mathrm{KtC}$ en el largo plazo. Al término de primer turno la diferencia se incrementa notable-mente tanto que al término del quinto turno alcanza $300 \mathrm{KtC}$. En la figura $10 \mathrm{se}$ observa su comportamiento notándose que el incremento tiende a ser mayor en el largo plazo; esa diferencia es una ganancia muy importante en la obtención de créditos en la captura de carbono mismos que se pueden perder en caso de tener un 30\% menor en los coeficientes de humificación y descomposición.

Para observar la sensibilidad de la captura de carbono a posibles diferencias en la parte inicial de las curvas del ICA se ajustó la curva estadística utilizada en la simulación base de acuerdo con los porcentajes de variación indicados anteriormente (por ejemplo, para el ICA al año 5 se usaron valores de $25 \%$ y $53 \%$ del valor a año 15). El resultado de este análisis, mostró una diferencia en la captura de carbono que va de $-10 \%$ a un $6 \%$ respecto a la estimación base. Como la diferencia no es cuantiosa, se consideró que los valores usados son adecuados para esta primera estimación del potencial de captura de carbono.

\section{DISCUSIÓN Y CONCLUSIONES}

El dióxido de carbono es el gas más importante en el efecto invernadero y por lo tanto uno de los responsables del posible cambio climático. Sin embargo, se tienen todavía incertidumbres muy importantes sobre las emisiones y captura de este gas, particularmente en los ecosistemas forestales. Por esta razón, se requiere de estudios de caso a nivel regional que conlleven a obtener datos más precisos sobre los flujos y almacenes de este gas en los bosques y selvas.

Como resultado del presente trabajo se estimó que:

- Al término del turno (50 años) la captura potencial de carbono para el bosque de Nuevo San Juan (NSJ) es de 1.5 millones de $\mathrm{tC}$, para una superficie de 8,870 ha del género Pinus. En el largo plazo (250 años) esta captura se estabiliza en 1.9 millones de $\mathrm{tC}$, equivalentes a $217 \mathrm{tC} / \mathrm{ha}$.

- Si se quisiera aumentar la captura potencial de carbono en el área de bosques naturales, la línea más promisoria sería derivar la cosecha de madera a productos con tiempo de residencia muy largos.

- El análisis de sensibilidad demuestra que la estimación base es bastante robusta a la variación de parámetros críticos. La mayor sensibilidad se presenta con respecto a las incertidumbres en las tasas de humificación y descomposición. 


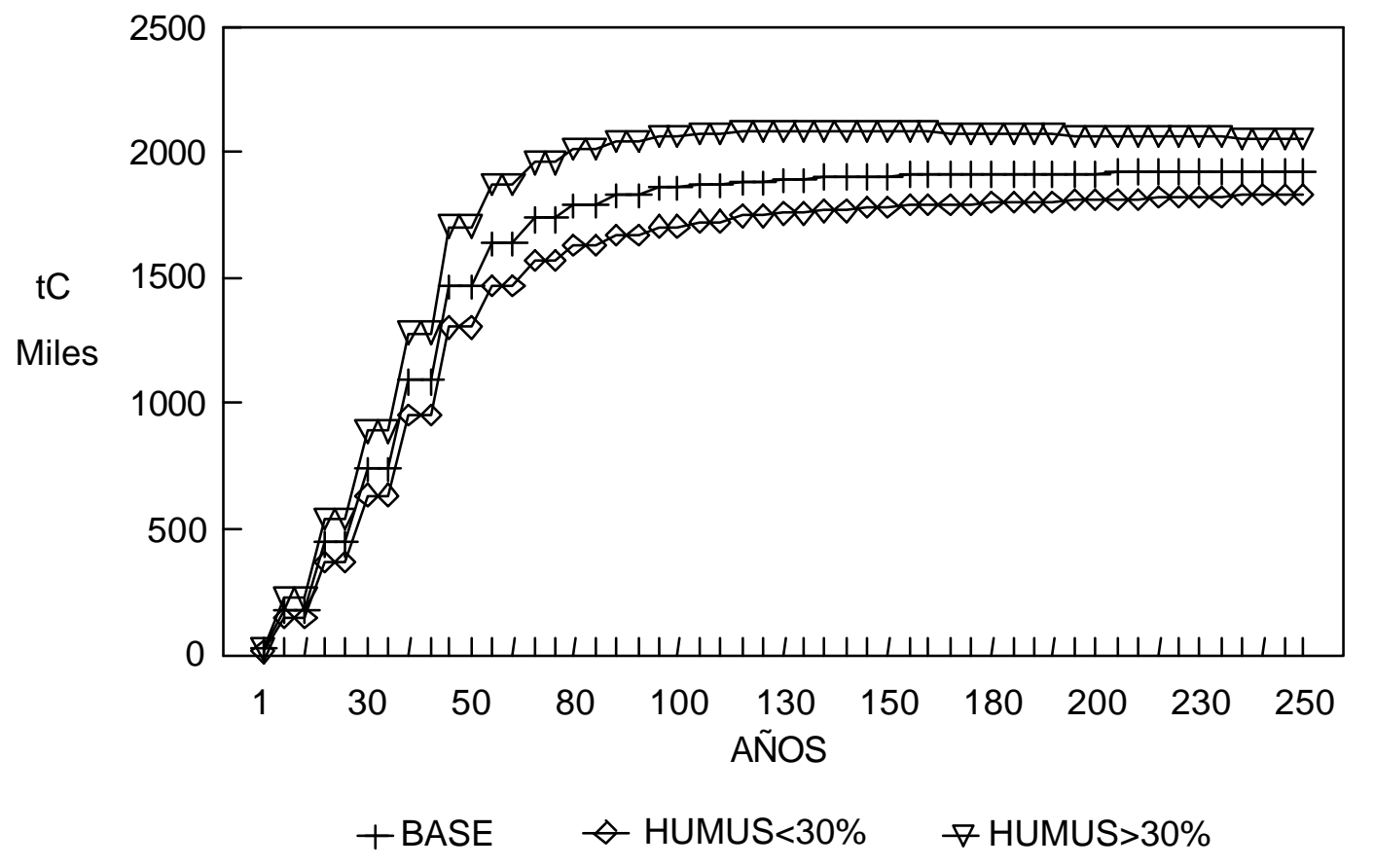

Figura 8. Sensibilidad del carbono contenido en la biomasa inicial del humus en tres casos: base, $-30 \%$ y $+30 \%$ respecto al base

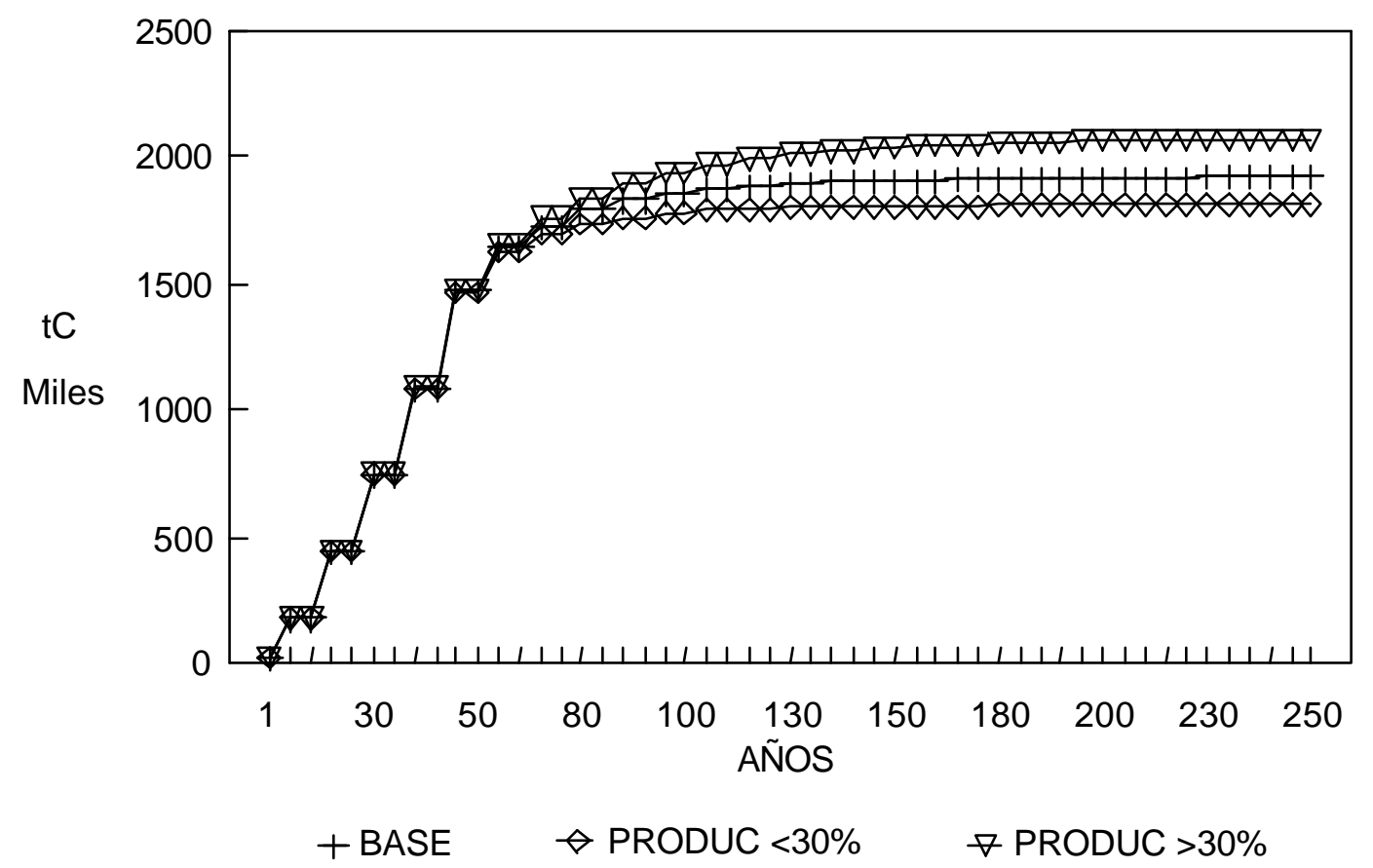

Figura 9. Sensibilidad en el tiempo de residencia promedio en los productos en tres casos: base, $-30 \%$ y $+30 \%$ respecto al base 


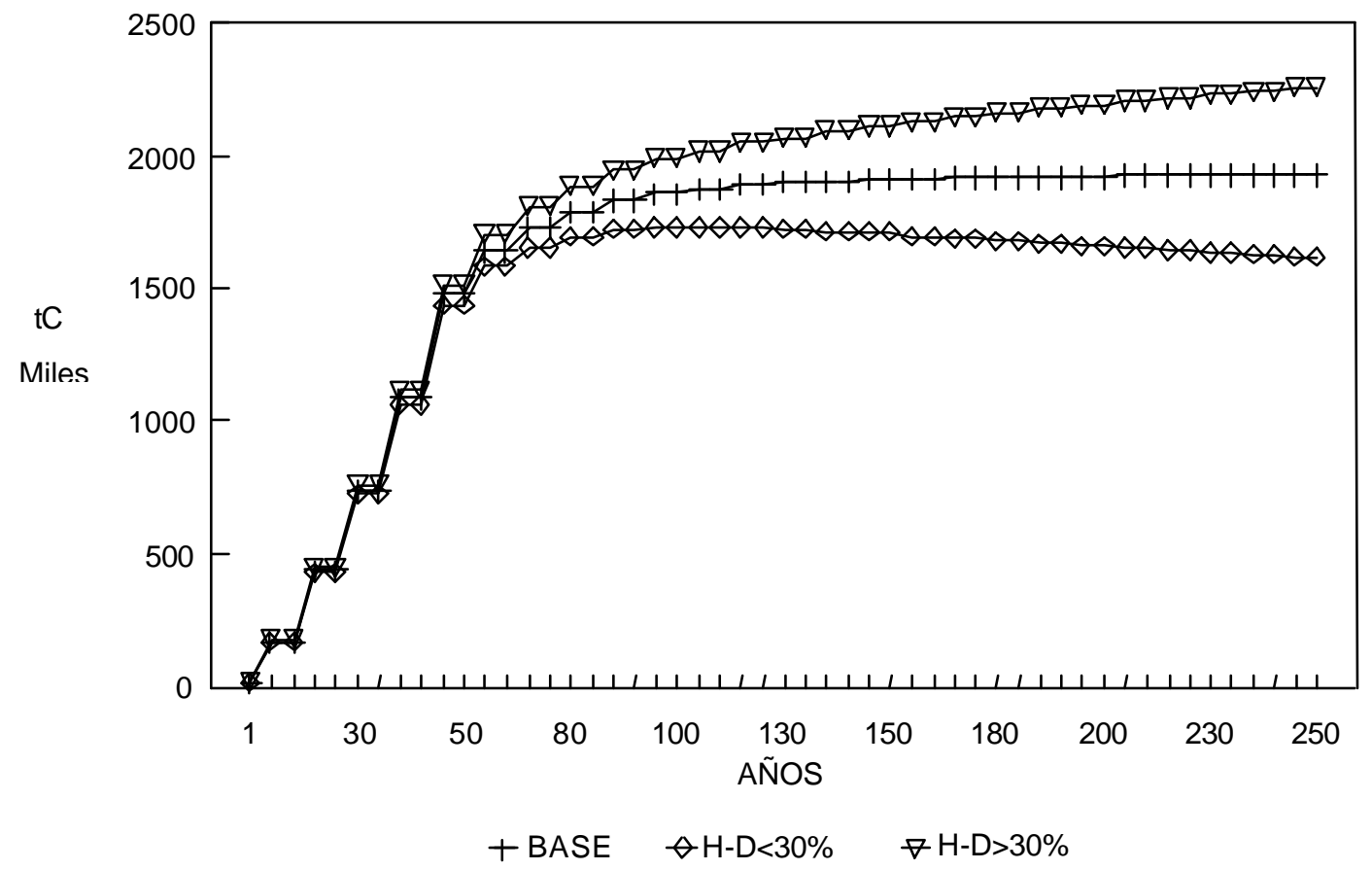

Figura 10. Sensibilidad en los coeficientes de humificación y descomposición en tres casos: base, $-30 \%$ y $+30 \%$ respecto al base

\section{Comparación de estimaciones de captura potencial de carbono con otros estudios}

Para saber si la estimación realizada por el modelo es cercana a estimaciones derivadas de muestreo directo, los resultados obtenidos en la captura de carbono en el largo plazo se compararon con estudios previos. El valor estimado para otras especies de Pinus es cercano a la estimación realizada en este estudio, siendo las 217 tC/ha un dato conservador. Es importante resaltar que estudios anteriores no contemplan el carbono almacenado en productos forestales, como en este estudio, a excepción del de Nabuurs y Morhen (1993) (Tabla 6).

\section{Comparación de escenarios alterna- tivos de captura potencial}

Los resultados obtenidos se compararon con dos escenarios: (a) se prolonga el turno de 50 a 80 años y (b) se asigna un tiempo de vida de 100 años a los productos. Como resultado de esta comparación, podemos concluir que alargar el ciclo de rotación produce solamente beneficios marginales en términos de la captura total de carbono y éstos se dan en el muy largo plazo. Por el contrario, transformar la madera extraída en productos de tiempos de vida muy largos produce una ganancia sustantiva en cuanto a la captura total de carbono en los bosques de la comunidad (Fig. 11).

Respecto al uso del modelo $\mathrm{CO}_{2} \mathrm{Fix}$, se pudo notar que su versión actual tiene ciertas limitaciones para la estimación de captura de carbono en bosques naturales. Específicamente, sólo trabaja con una especie forestal y no incluye la biomasa contenida en sotobosque. Sería conveniente que futuras versiones del modelo permitan integrar más especies forestales, incluir la biomasa contenida en sotobosque y estimar la captura neta al 
Tabla 6. Comparación de resultados con estudios previos

\begin{tabular}{|c|c|c|c|c|c|}
\hline VEGETACIÓN & $\begin{array}{c}\text { BIOMASA } \\
\text { (tC/ha) }\end{array}$ & $\begin{array}{l}\text { SUELO } \\
\text { (tC/ha) }\end{array}$ & $\begin{array}{c}\text { PRODUCTOS } \\
\text { (tC/ha) }\end{array}$ & $\begin{array}{l}\text { TOTAL } \\
\text { (tC/ha) }\end{array}$ & FUENTE \\
\hline Bosque de pino & 120 & 156 & n.d. & 276 & a \\
\hline Bosque de pino-encino & 135 & 151 & n.d. & 286 & a \\
\hline Bosque de templado primario & 123 & 134 & n.d. & 257 & b \\
\hline Bosque templado secundario & 90 & 120 & n.d. & 210 & b \\
\hline Picea abies & 225 & 121 & c.b & 346 & c \\
\hline Pinus radiata en plantación & 136 & 81 & c.b. & 217 & c \\
\hline Pinus caribea & 145 & 91 & c.b. & 236 & c \\
\hline Pinus pseudostrobus & 74 & 94 & 49 & 217 & Este estudio \\
\hline $\begin{array}{l}\text { Fuente } \\
\text { a De Jong et al., } 1997 \\
\text { b Nilsson y Schopfhauser, } 1995 \\
\text { c Nabuurs y Morhen, } 1993 \\
\text { n.d. No disponible } \\
\text { c.b. Contenido en la biomasa. }\end{array}$ & & & & & \\
\hline
\end{tabular}

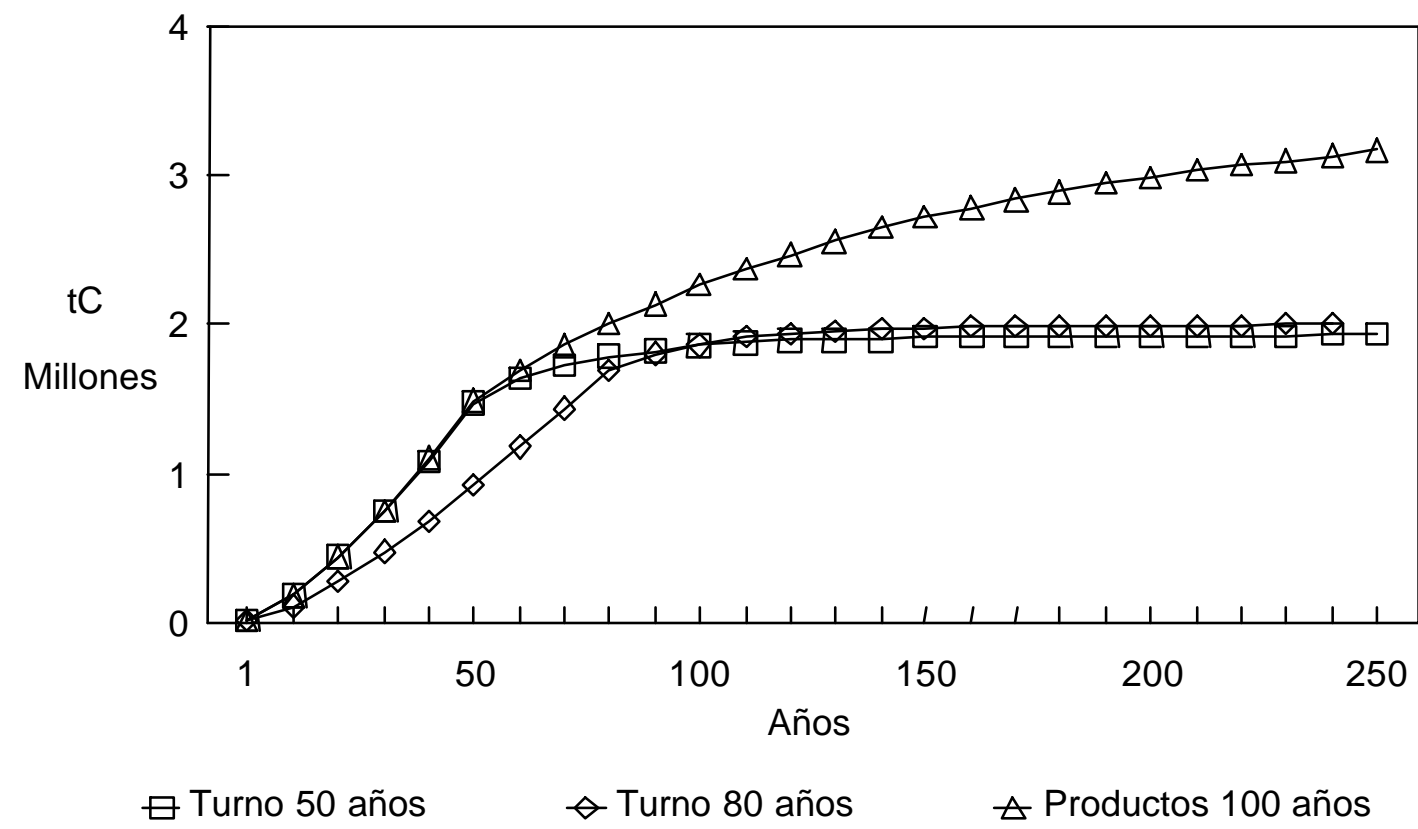

Figura 11. Análisis comparativo de los dos turnos y el incremento en la vida de los productos 
considerar la biomasa inicial y restarla de la biomasa final.

En cuanto a las ventajas del modelo, además de permitir estimar el potencial de captura de carbono, se tiene que:

- Permite generar escenarios predictivos de la captura de carbono a corto, mediano y largo plazo, proyectando las tendencias del manejo forestal por tipo de especie forestal.

- Por su estructura también permite realizar análisis de sensibilidad sobre parámetros que pueden presentar incertidumbre de una manera mejorada y relativamente sencilla.

El presente estudio brinda una primera aproximación al potencial de captura de carbono en la comunidad indígena de NSJ. En estudios posteriores deberá extenderse la estimación de este potencial de captura a otros géneros como los encinos y a las plantaciones que actualmente ha establecido la comunidad. Asimismo sería conveniente usar datos sobre el contenido de carbono en el suelo y sobre tasas de humificación y descomposición de la localidad y no de la literatura.

Para aplicar las estrategias de mitigación propuestas en los rubros de conservación y reforestación, sería conveniente evaluar la captura neta, estableciendo una línea base de captura de carbono en el bosque de NSJ, con el fin de monitorear las emisiones evitadas con base en las actividades que realiza la comunidad. En este trabajo, no fue posible desarrollar una línea de base por el costo que esto implica, además de la necesidad de integración de un equipo multidisciplinario (Tipper y de Jong; Tipper et al., 1998).

Finalmente, si se toma en cuenta que a nivel internacional se ha fijado un precio aproximado de US \$10/tC por concepto de captura de carbono como "servicio ambiental" en proyectos forestales
(Montoya et al., 1995; De Jong et al., 1998), se generaría una derrama económica considerable para la C.I. de NSJ. De hecho, considerando una captura neta fuera de alrededor de $100 \mathrm{tC} / \mathrm{ha}$, los beneficios estimados serían del orden de $\$ 9$ millones de dólares por lo menos. Este recurso ayudaría a conservar los bosques de la comunidad y seguir obteniendo otros beneficios como: conservación de suelo, acumulación de agua, almacenamiento y reciclaje de nutrientes, limpieza del aire y sobre todo conservación y mantenimiento de la riqueza y diversidad biológica del lugar.

\section{REFERENCIAS}

Apps, M.J., W.A. Kurz, R.J. Luxmoore, L.O. Nilsson, R.A. Sedjo, R. Schmidt, L.G. Simpson y T.S. Vinson. 1993. Boreal Forests and Tundra. In: Wisniewski, J. y R.N. Sampson (Eds). Terrestrial Biospheric Carbon Fluxes: Quantification and Sources of $\mathrm{CO}_{2}$. Kluwer Academic Publishers. Holanda. p: 39-53.

Bello, M.A. y J.N. Labat. 1987. Los encinos (Quercus) del Estado de Michoacán, México. Instituto Nacional de Investigaciones Forestales y Agropecuarias. SARH y Centre D'Etudes Mexicaines et Centroamericaines. Collection Etudes Mesoamericaines. México. 98 pp.

Bolin, B., B.R. Döös; J. Jager y R.A. Warrick. 1986. The Greenhouse effect, climate change and ecosystems. Ed. John Wiley \& Sons.

Brown, S., Ch. Hall, W. Knabe, J. Raich; M. Trexler y P. Woomer. 1993. Tropical forest: their past, present and potential future role $\ln$ : The Terrestrial Carbon Budget. Water, Air and Soil Pollution 70: 71-94.

Cherrill, A. y C. McClean. 1995. An investigation of uncertainty in field habitat mapping and the implications 
for detecting land cover change. Landscape Ecology 10(1): 5-21.

Cuanalo de la C.H., E.T. Ojeda, A.O. Santos y C.A. Ortiz. 1989. Provincias y subregiones terrestres de México. Colegio de Postgraduados. Centro de Ecología. Chapingo, Edo. de México. $624 \mathrm{p}$.

De Jong, B., G. Montoya G., K. Nelson, L. Soto P., J. Taylor y R. Tipper. 1995. Community forest management and carbon sequestration: a feasibility study from Chiapas, Mexico. Interciencia 20(6): 409-416.

De Jong, B., M.A. Cairns, N. Ramírez M., S. Ochoa G., J. Mendoza V., P.K. Haggerty, M. González E. e I. March Mifsut. 1998. Land-use change and carbon flux between the 1970s and 1990s in the central highlands of Chiapas. Mexico. Environmental Management (Aceptado Junio 4, 1998).

Dixon, R.K., S. Brown, R.A. Houghton, A.M. Solomon, M.C. Trexler y J. Wisniewski. 1994. Carbon pools and flux of global forest ecosystems. Science 263: 185-190.

García O. F. y A. Ordóñez. 1999. El papel de los suelos forestales en la captura de carbono. Enviada a Nuestros Bosques.

García, E. 1981. Modificaciones al sistema de clasificación climática de Köppen (para adaptarlo a las condiciones de la República Mexicana). México, D.F. Offset Larios. 3 ${ }^{a}$ ed. Corregida y aumentada 1988.

Gay, C. y J. Martínez. 1995. Mitigation of emissions of gereenhouse gases in Mexico. Interciencia, 20(6):336-342.

Grijpma, I.P. 1984. Producción forestal. Ed Secretaría de Educación Pública (SEP)/Trillas. 3a Reimpresión. México, D.F. 134 p.
Goudie, A. 1990. The human impact on the natural environment. Basil Blackwell Ltd. $3^{\mathrm{a}}$ Edition. Oxford, Reino Unido. 388 p.

Houghton, R.A. y C.M. Woodwell. 1989. Global Climate Change. Scientific American 260(4): 36-40.

Intergovernmental Panel on climate change (IPCC). 1995. Climate change 1995. The Supplementary Report to the IPCC Scientific Assessment. Cambridge University Press. Cambridge.

Krysanova, V., W. Mueller y A. Becker. 1998. Development and test of a spatially distributed hydrological/ water quality model for mesoscale watersheds. Ecological-Modelling 106 (3-2): 261-289.

Lashof, D.A y D.R. Ahuja. 1990. Relative contributions of greenhouse gas emissions to global warming. Nature 344(5): 529-531.

Madrigal S., X. 1982. Claves para la identificación de las coníferas silvestres del Estado de Michoacán. Universidad Michoacana de San Nicolás de Hidalgo. 100 p.

Mander, U., A. Kull, V. Tamm, V. Kuusements y R. Karjus. 1998. Impact of climatic fluctuations and land use change on runoff and nutrient losses in rural landscapes. Landscape and Urban Planning 41(34):229-238.

Masera, O., M.R. Bellon y G. Segura W. 1995a. Forest management options for sequestering carbon in Mexico. Biomass \& Bioenergy 8(5): 357-367.

Masera, O.R., T. Hernández, A. Ordóñez y A. Guzmán. 1995b. Land use change and forestry. In: Preliminary National Inventory of Greenhouse Gases: Mexico. UNEP PROJECT GF/410292-01(PP/3011). Instituto Nacional de 
Ecología. Programa de las Naciones Unidas para el Medio Ambiente. U.S. Country Studies Program. September. Mexico, D.F.

Masera, O.R. 1996. Desforestación y Degradación Forestal en México. Documento de Trabajo No. 19. GIRA, A.C. Pátzcuaro, México.

Masera, O.R. y J.A. Ordóñez. 1996. Bosques y cambio climático global: Referencias seleccionadas. Reporte al Proyecto Estudio de país sobre cambio climático global. Instituto Nacional de Ecología. U.S Environmental Protection Agency.

Masera O., M.J. Ordóñez y R. Dirzo. 1997. Carbon emissions from Mexican forests: current situation and longterm scenarios. Climatic Change 35: 265-295.

Mintzer, I.M. 1992. Confronting climate change. risk implications and responses. Cambridge University Press. Cambridge.

Morhen, G.M.J., J.F. Garza, O. Masera y G.J. Nabuurs. 1997. User's Manual CO2Fix For Windows: a dynamic model of the CO2-fixation in forest stands. Version 1.2. IBN Research Report. Instituto de Ecología de la UNAM. 26 p.

Mohren, G.M.J. y C.G.M. Klein Goldewijk. 1990. $\mathrm{CO}_{2}$ Fix: A dynamic model of the $\mathrm{Co} 2$ fixation in forest stands. Report NR. 624. Research Institute for Forestry and Urban Ecology, Wageningen.

Nabuurs, G.J. y G.M.J. Mohren. 1993. Carbon fixation through forestation activities: A study of the carbon sequestering potential of selected forest types. Commissioned by the Foundation Face. Report IBN 93/4. Institute for Forestry and Nature Research, Forests Absorbing
Carbondioxyde Emission. Holanda. $206 \mathrm{p}$.

Nilsson, S. y W. Schopfhauser. 1995. The carbon-sequestration potential of a global afforestation program. Climatic Change 30, 267-293.

Ordóñez, A. 1999. Captura de carbono en un bosque templado: El caso de San Juan Nuevo, Michoacán. Instituto Nacional de Ecología. SEMARNAP. México D.F. Junio. $72 \mathrm{p}$.

Ordóñez, A. 1998. Estimación de la captura de carbono en un estudio de caso para bosque templado: San Juan Nuevo, Michoacán. Tesis de Licenciatura. Facultad de Ciencias. UNAM. México, D.F.

Ordóñez, A. 1998. El modelo $\mathrm{CO}_{2} \mathrm{Fix}$. Memorias del Taller de metodologías para la evaluación de la captura de carbono en el área forestal. México, D.F. Instituto Nacional de EcologíaSEMARNAP. Marzo 19-20.

Ordóñez, A. 1997. Estimación del potencial de captura de carbono. Memorias del Taller de Captura de carbono para la región de los Tuxtlas. Veracruz, Ver. Instituto Nacional de Ecología-SEMARNAP. agosto 8.

Ordóñez, A. 1997. El Modelo $\mathrm{CO}_{2}$ Fix. http://www.ine.gob.mx/INE/document os/ucci/cam_clima/chi18.htm

Ordóñez, A. 1997. Estimación del potencial de captura de carbono para un estudio de caso de bosque templado en Nuevo Parangaricutiro, Mich. Resultados Preliminares. Memorias del Taller sobre Proyectos de Secuestro de Carbono e Implementación Conjunta. Tuxtla Gutiérrez, Chiapas. Abril 11-12.

Secretaría de Agricultura y Recursos Hidráulicos (SARH). 1988. Estudio de manejo integral del recurso 
forestal en la comunidad indígena de Nuevo San Juan, Michoacán, Municipio de Nuevo San Juan, Michoacán. Jefatura del Programa Forestal en el estado de Michoacán. Distrito de Desarrollo Rural Integral No. 087. Uruapan, Michoacán. Comisión de Silvicultura de la comunidad indígena Nuevo San Juan, Michoacán. 800 p.

Tipper, R. y B.H. de Jong. 1998. Quantification and regulation of carbon offsets from forestry: comparison of alternative methodologies, with special reference to Chiapas, Mexico. Commonwealth Forestry Review 77(3): 219-227.

Tipper, R., BH de Jong, S. Ochoa G. M.L. Soto P., M.A. Castillo S., G. Montoya G. y I. March :M. 1998. Assessment of the cost of large scale forestry for $\mathrm{CO}_{2}$ sequestration: evidence from Chiapas, Mexico. IEA Greenhouse Gas R\&D Programme. 84 p.

Schneider, S.H. 1989. The greenhouse effect: science and policy. Science, 243(10): 271-281

Varela, S.; P. García; R. Cardoza y V. Sosa. 1995. Marco de referencia sobre estimaciones de desforestación en México. Documento presentado al Grupo de trabajo sobre deforestación. Secretaría del Medio Ambiente, Recursos Naturales y Pesca (SEMARNAP). México, D.F.

Wilson E.O. 1999. The diversity of life. W.W. Norton \& Co. New York. 424 p. Tropical Forest Update 8(1) 2-5. $\diamond$

1 Laboratorio de Bioenergía. Instituto de Ecología. UNAM. Sur No. 43. Col. Minerva. 09810 México D.F. México.c.e.: bordonez@miranda.ecologia.unam.mx.

2 El Colegio de la Frontera Sur. Unidad Villahermosa. Mario Brown Peralta \# 209-E, Fraccionamiento Guadalupe. 86180 Villahermosa, Tabasco. México. c.e.: bjong@sclc.ecosur.mx.

Manuscrito recibido el 12 septiembre de 2000

Aceptado el 23 de febrero 2001

Este documento se debe citar como:

Ordóñez, B.; H.J de Jong y O. Masera. 2001. Almacenamiento de carbono en un bosque de Pinus pseudostrobus, Michoacán. Madera y Bosques 7(2):27-47. 